\title{
IDENTIFIKASI DAN PENETAPAN KADAR RHODAMIN B PADA JAJANAN KUE BERWARNA MERAH MUDA YANG BEREDAR DI KOTA MANADO
}

\author{
Paulina V. Y. Yamlean ${ }^{1)}$ \\ ${ }^{1)}$ Program Studi Farmasi FMIPA Universitas Sam Ratulangi Manado, 95115 \\ Email:olan_0506@yahoo.co.id
}

\begin{abstract}
ABSTRAK
Rhodamin B adalah pewarna terlarang yang sering ditemukan pada makanan, terutama makanan jajanan. Rhodamin B, yaitu zat pewarna berupa serbuk kristal berwarna hijau atau ungu kemerahan, tidak berbau, serta mudah larut dalam larutan warna merah terang berfluoresan sebagai bahan pewarna tekstil atau pakaian. Jenis jajanan yang banyak dijumpai dan dicampuri dengan Rhodamin B, antara lain bubur delima, cendol, kolang-kaling, cincau dan kue-kue lainnya. Setelah dicampuri bahan ini makanan tersebut menjadi berwarna merah muda terang. Hasil penelitian yang diperoleh membuktikan bahwa sampel-sampel kue berwarna merah muda yang beredar di kota Manado ada yang positif menggunakan Rhodamin B.
\end{abstract}

Kata kunci: kue berwarna merah muda, rhodamin B

\section{IDENTIFICATION AND DETERMINATION LEVEL OF RHODAMIN B ON STREET FOOD PINC CAKE THAT CIRCULATION TO MANADO CITY}

\begin{abstract}
Rhodamin B is the illegal dyes that is often found in food, especially street foods. Rhodamin B, which is a dye form crystalline powder colored green or reddish purple, odorless, easily soluble in bright red fluoroscence solution as dye of textiles or apparel. Types of street food that are often found and mixed with Rhodamin B, amon pomegranate porridge, cendol, fro, grass jelly and other pastries. After mix with Rhodamon B, all that food becomes light pink. The results of research has obtained prove that the samples pink cake that circulated in Manado citythere are positive use of Rhodamin B.
\end{abstract}

Keywords: pink cake, rhodamin B

\section{PENDAHULUAN}

\section{Latar Belakang}

Makanan merupakan salah satu kebutuhan dasar manusia yang terpenting dan juga merupakan faktor yang sangat esensial bagi pertumbuhan dan perkembangan manusia. Tetapi betapapun menariknya penampilan, lezat rasanya dan tinggi nilai gizinya, apabila tidak aman dikonsumsi, maka makanan tersebut tidak ada nilainya sama sekali (Winarno dan Rahayu, 1994).

Salah satu masalah pangan yang masih memerlukan pemecahan yaitu penggunaan bahan tambahan pangan untuk berbagai keperluan. Penggunaan bahan tambahan pangan dilakukan pada industri pengolahan pangan, maupun dalam pembuatan makanan jajanan, yang umumnya dihasilkan oleh industri kecil atau rumah tangga (Anonim, 2005).

Makanan jajanan (street food) sudah menjadi bagian yang tidak terpisahkan dari kehidupan masyarakat, baik dari perkotaan maupun pedesaan. Keunggulan dari makanan jajanan adalah murah dan mudah didapat, serta cita rasanya yang cocok dengan selera kebanyakan masyarakat. Meskipun makanan jajanan memiliki keunggulan-keunggulan tersebut, ternyata makanan jajanan juga beresiko terhadap kesehatan karena penanganannya sering tidak higienis, yang memungkinkan makanan jajanan terkontaminasi oleh mikroba beracun maupun penggunaan bahan tambahan pangan (BTP) yang tidak diizinkan (Anonim, 2005).

Rhodamin B adalah pewarna terlarang yang sering ditemukan pada makanan, terutama makanan jajanan. 
Rhodamin B, yaitu zat pewarna berupa serbuk kristal berwarna hijau atau ungu kemerahan, tidak berbau, serta mudah larut dalam larutan warna merah terang berfluoresan sebagai bahan pewarna tekstil atau pakaian. Jenis jajanan yang banyak dijumpai dan dicampuri dengan Rhodamin B, antara lain bubur delima, cendol, kolangkaling, cincau dan kue-kue lainnya. Setelah dicampuri bahan ini makanan tersebut menjadi berwarna merah muda terang (Anonim, 2008; Anonima, 2006).

Penggunaan Rhodamin B pada makanan dalam waktu yang lama akan dapat mengakibatkan gangguan fungsi hati maupun kanker. Namun demikian, bila terpapar Rhodamin B dalam jumlah besar maka dalam waktu singkat akan terjadi gejala akut keracunan Rhodamin B (Yuliarti, 2007).

Berdasarkan permasalahan di atas maka perlu dilakukan penelitian untuk mengidentifikasi Rhodamin B pada jajanan kue berwarna merah muda yang beredar di kota Manado.

Tujuan dari penelitian ini adalah: 1) Untuk mengetahui ada tidaknya pewarna Rhodamin B pada jajanan kue berwarna merah muda yang beredar di kota Manado; 2) Untuk mengetahui seberapa besar kadar zat warna Rhodamin B pada jajanan kue berwarna merah muda yang beredar di kota Manado.

\section{METODOLOGI PENELITIAN}

Alat

Alat yang digunakan dalam penelitian ini adalah: Erlenmeyer, Hot plate, Timbangan, Corong pisah, Spektrofotometer UV-Vis Milton Roy 501, Labu takar, Gelas arloji, Gelas ukur, Pipet, Spatula, Batang pengaduk, Kertas saring Whatman No. 42.

\section{Bahan}

Bahan-bahan yang digunakan adalah: Kue ku dan kue bolu kukus, Dietil eter, Aquades, Larutan natrium hidroksida 10\%, Larutan natrium hidroksida $0,5 \%$, Larutan asam klorida $0,1 \mathrm{~N}$, Larutan ammonia $2 \%$ dalam etanol $70 \%$.

\section{Variabel yang Diamati}

$\mathrm{A}_{1}$ : kue ku dari pasar Karombasan pada penjual I

$\mathrm{A}_{2}$ : kue bolu kukus dari pasar Karombasan pada penjual I

$\mathrm{B}_{1}$ : kue ku dari pasar Karombasan pada penjual II

$\mathrm{B}_{2}$ : kue bolu kukus dari pasar Karombasan pada penjual II

$\mathrm{C}_{1}$ : kue ku dari pasar Bahu pada penjual I

$\mathrm{C}_{2}$ : kue bolu kukus dari pasar Bahu pada penjual I

$\mathrm{D}_{1}$ : kue ku dari pasar Bahu pada penjual II

$\mathrm{D}_{2}$ : kue bolu kukus dari pasar Bahu pada penjual II

$\mathrm{E}_{1}$ : kue ku dari paar Bersehati pada penjual I

$\mathrm{E}_{2}$ : kue bolu kukus dari pasar Bersehati pada penjual I

$F_{1}$ : kue ku dari pasar Bersehati pada penjual II

$\mathrm{F}_{2}$ : kue bolu kukus dari pasar Bersehati pada penjual II

$\mathrm{G}_{1}$ : kue ku dari pasar Tuminting pada penjual I

$\mathrm{G}_{2}$ : kue bolu kukus dari pasar Tuminting pada penjual I

$\mathrm{H}_{1}$ : kue ku dari pasar Tuminting pada penjual II

$\mathrm{H}_{2}$ : kue bolu kukus dari pasar Tuminting pada penjual II

\section{Identifikasi Zat Warna}

Prinsip kerja dalam identifikasi zat warna Rhodamin B pada jajanan kue akan menggunakan identifikasi secara spektrofotometer UV-Vis setelah diekstraksi dan dimurnikan.

\section{Prosedur Kerja}

\section{Pengambilan dan Penyiapan Sampel}

Sampel kue ku dan bolu kukus diambil pada dua penjual jajanan kue di empat pasar yang ada di kota Manado yaitu pasar Karombasan, pasar Bahu, pasar Bersehati dan pasar Tuminting, pada tanggal 1 November 2008. Sampel kue ku diambil sebanyak 2 buah dan sampel kue bolu kukus diambil sebanyak 8 buah pada tiap-tiap penjual kemudian sampel dimasukkan ke dalam wadah plastik dan selanjutnya dibawa ke laboratorium Kimia Lanjut FMIPA UNSRAT. 


\section{Ekstraksi dan Pemurnian}

\section{a. Pembuatan larutan uji}

Sejumlah 5 gram sampel kue ditimbang saksama kemudian sampel dimasukkan ke dalam erlenmeyer $250 \mathrm{ml}$ yang bertutup asah dan masing-masing wadah diberi label. Sampel kemudian ditambahkan $100 \mathrm{ml}$ larutan ammonia 2\% dalam etanol $70 \%$ dan didiamkan semalam hingga semua pewarna larut. Larutan berwarna disaring dengan menggunakan kertas saring Whatman ke dalam erlenmeyer. Hasil penyaringan tersebut dipindahkan ke gelas ukur kemudian diuapkan di atas hot plate selama 4 jam pada suhu $65^{\circ} \mathrm{C}$. Sampel yang menjadi pekat selama proses penguapan kemudian dilarutkan dengan $30 \mathrm{ml}$ aquades sambil diaduk dengan batang pengaduk. Larutan dimasukkan ke dalam corong pisah $250 \mathrm{ml}$, kemudian ditambahkan $6 \mathrm{ml}$ larutan natrium hidroksida $10 \%$ dan dikocok. Larutan diekstraksi dengan $30 \mathrm{ml}$ dietil eter kemudian dikocok dan didiamkan hingga larutan membentuk 2 lapisan yaitu lapisan eter jernih (atas) dan lapisan air berwarna merah (bawah). Lapisan air kemudian dibuang melalui kran corong pisah sehingga hanya terdapat lapisan eter yang disebut ekstrak eter. Ekstrak eter dicuci dengan larutan $\mathrm{NaOH}$ 0,5\% sebanyak $5 \mathrm{ml}$ dengan cara dikocok kemudian diamkan. Dari pencucian tersebut maka akan terbentuk 2 lapisan lagi yaitu lapisan eter jernih (atas) dan lapisan air berwarna kecoklatan (bawah). Lapisan air bagian bawah dibuang melalui kran corong pisah sehingga hanya terdapat ekstrak eter yang kemudian diekstraksi 3 kali, tiap kali dengan $10 \mathrm{ml}$ asam klorida $0,1 \mathrm{~N}$ hingga lapisan eter tidak berwarna lagi. Lapisan eter dibuang, ekstrak asam klorida ditampung dalam labu tentukur $50 \mathrm{ml}$ dan ditambahkan asam klorida $0,1 \mathrm{~N}$ sampai tanda.

\section{b. Pembuatan larutan baku}

Larutan baku rhodamin B dibuat dengan konsentrasi $1000 \mathrm{mg} / \mathrm{l}$. Dari larutan baku ini dibuat larutan baku antara dengan kadar $20 ; 40 ; 80 ; 120 \mu \mathrm{g} / \mathrm{ml}$. Selanjutnya dibuat satu seri larutan baku kerja dengan konsentrasi masing-masing 0,$4 ; 0,8 ; 1,6 ; 2,4$ $\mu \mathrm{g} / \mathrm{ml}$. Sebagai pelarut digunakan larutan $\mathrm{HCl}$ $0,1 \mathrm{~N}$.

\section{c. Penetapan Kadar Zat Warna Rhodamin B}

Cara penetapan kadar Rhodamin B yaitu masing-masing larutan diukur secara spektrofotometri cahaya tampak pada panjang gelombang $538 \mathrm{~nm}$. Sedangkan untuk menghitung kadar Rhodamin B dalam sampel dihitung dengan menggunakan kurva kalibrasi dengan persamaan regresi : $\mathrm{y}=\mathrm{bx} \pm$ a (Anonimc, 2006).

Tabel 1. Hasil analisis Rhodamin B pada jajanan kue di pasar Karombasan

\begin{tabular}{|c|c|c|c|c|c|}
\hline Sampel & $\begin{array}{c}\text { Keterangan } \\
\text { warna larutan } \\
\text { uji }\end{array}$ & Perlakuan & $\begin{array}{c}\text { Absorba } \\
\mathbf{n s i}\end{array}$ & $\begin{array}{c}\text { Kadar } \\
(\boldsymbol{\mu} \mathbf{g} / \mathbf{m l})\end{array}$ & $\begin{array}{c}\text { Rata-rata } \\
(\boldsymbol{\mu g} / \mathbf{m l})\end{array}$ \\
\hline $\mathrm{A}_{1}$ & Bening & 1 & 0,000 & - & - \\
\hline $\mathrm{A}_{2}$ & Merah muda & 1 & 0,000 & - & \\
\hline $\mathrm{B}_{1}$ & Bening & 1 & 0,097 & 0,0019798 & 0,0019798 \\
& & 2 & 0,000 & 0,0019798 & - \\
\hline $\mathrm{B}_{2}$ & Kemerahmudaan & 1 & 0,000 & - & - \\
\hline Baku & Merah muda & 1 & 0,003 & 0,0011879 & 0,0011963 \\
standar & & & 0,490 & 0,0012047 & \\
\hline
\end{tabular}

Keterangan:

$\mathrm{A}_{1}$ : Kue ku dari pasar Karombasan pada penjual I; $\mathrm{A}_{2}$ : Kue bolu kukus dari pasar Karombasan pada penjual I; $\mathrm{B}_{1}$ : Kue ku dari pasar Karombasan pada penjual II; $\mathrm{B}_{2}$ : Kue bolu kukus dari pasar Karombasan pada penjual II 


\section{HASIL DAN PEMBAHASAN}

Hasil analisis kualitatif Rhodamin B pada jajanan kue berwarna merah muda, diambil dari 2 penjual jajanan kue yang beredar di kota Manado yaitu pasar
Karombasan, pasar Bahu, pasar Bersehati dan pasar Tuminting. Analisis dilakukan sebanyak 2 kali pengujian (duplo) dengan menggunakan spektrofotometer UV-Vis. Hasilnya dapat dilihat pada Tabel 1.

Tabel 2. Hasil analisis Rhodamin B pada jajanan kue di pasar Bahu

\begin{tabular}{|c|c|c|c|c|c|}
\hline Sampel & $\begin{array}{c}\text { Keterangan } \\
\text { warna larutan uji }\end{array}$ & Perlakuan & $\begin{array}{c}\text { Absorba } \\
\text { nsi }\end{array}$ & $\begin{array}{l}\text { Kadar } \\
(\mu \mathrm{g} / \mathrm{ml})\end{array}$ & $\begin{array}{c}\text { Rata-rata } \\
(\mu \mathrm{g} / \mathrm{ml})\end{array}$ \\
\hline $\mathrm{C}_{1}$ & Bening & $\begin{array}{l}1 \\
2\end{array}$ & $\begin{array}{l}0,000 \\
0,000\end{array}$ & - & - \\
\hline $\mathrm{C}_{2}$ & Bening & $\begin{array}{l}1 \\
2\end{array}$ & $\begin{array}{l}0,000 \\
0,000\end{array}$ & - & - \\
\hline $\mathrm{D}_{1}$ & Bening & $\begin{array}{l}1 \\
2\end{array}$ & $\begin{array}{l}0,000 \\
0,000\end{array}$ & $\begin{array}{l}- \\
-\end{array}$ & - \\
\hline $\mathrm{D}_{2}$ & Bening & $\begin{array}{l}1 \\
2\end{array}$ & $\begin{array}{l}0,000 \\
0.000\end{array}$ & - & - \\
\hline $\begin{array}{c}\text { Baku } \\
\text { standar }\end{array}$ & Merah muda & 1 & 0,490 & 0,0052906 & - \\
\hline
\end{tabular}

Keterangan:

$\mathrm{C}_{1}$ : Kue ku dari pasar Bahu pada penjual I; $\mathrm{C}_{2}$ : Kue bolu kukus dari pasar Bahu pada penjual I;

$\mathrm{D}_{1} \quad$ : Kue ku dari pasar Bahu pada penjual II; $\mathrm{D}_{2}$ : Kue bolu kukus dari pasar Bahu pada penjual II

Tabel 3. Hasil analisis Rhodamin B pada jajanan kue di pasar Bersehati

\begin{tabular}{|c|c|c|c|c|c|}
\hline Sampel & $\begin{array}{c}\text { Keterangan } \\
\text { warna larutan uji }\end{array}$ & Perlakuan & $\begin{array}{c}\text { Absorb } \\
\mathbf{a n s i}\end{array}$ & $\begin{array}{c}\text { Kadar } \\
(\boldsymbol{\mu g} / \mathbf{m l})\end{array}$ & $\begin{array}{c}\text { Rata-rata } \\
(\boldsymbol{\mu g} / \mathbf{m l})\end{array}$ \\
\hline $\mathrm{E}_{1}$ & Bening & 1 & 0,000 & - & - \\
& & 2 & 0,000 & - & \\
\hline $\mathrm{E}_{2}$ & Kemerahmudaan & 1 & 0,009 & 0,0012384 & 0,00123415 \\
& & 2 & 0,008 & 0,0012299 & \\
\hline $\mathrm{F}_{1}$ & Bening & 1 & 0,000 & - & - \\
& & 2 & 0,000 & - & \\
\hline $\mathrm{F}_{2}$ & Kemerahmudaan & 1 & 0,007 & 0,0012216 & 0,00122575 \\
& & 2 & 0,008 & 0,0012299 & \\
\hline Baku & Merah muda & 1 & 0,490 & 0,0052906 & - \\
standar & & & & & \\
\hline
\end{tabular}

Keterangan:

- $\quad \mathrm{E}_{1} \quad$ : Kue ku dari pasar Bersehati pada penjual I

- $\quad \mathrm{E}_{2} \quad$ : Kue bolu kukus dari pasar Bersehati pada penjual I

- $\mathrm{F}_{1} \quad$ : Kue ku dari pasar Bersehati pada penjual II

- $\mathrm{F}_{2} \quad$ : Kue bolu kukus dari pasar Bersehati pada penjual II

Identifikasi Rhodamin B pada jajanan kue telah dilakukan dengan menggunakan sampel kue ku dan kue bolu kukus yang diambil dari dua penjual jajanan kue di empat pasar yang ada di kota Manado.

Hasil penelitian yang diperoleh membuktikan bahwa sampel-sampel kue berwarna merah muda yang beredar di kota Manado ada yang positif menggunakan
Rhodamin B. Sampel yang positif menggunakan Rhodamin B yaitu sampel kue bolu kukus yang diambil di pasar Karombasan, pasar Bersehati dan pasar Tuminting (Tabel 1, Tabel 3, Tabel 4). Hal ini dibuktikan dengan hasil analisis jajanan kue berwarna merah muda tersebut menggunakan spektrofotometer UV-Vis dengan 2 kali pengujian (duplo). 
Tabel 4. Hasil analisis Rhodamin B pada jajanan kue di pasar Tuminting

\begin{tabular}{|c|c|c|c|c|c|}
\hline Sampel & $\begin{array}{c}\text { Keterangan } \\
\text { warna larutan uji }\end{array}$ & Perlakuan & $\begin{array}{c}\text { Absorba } \\
\mathbf{n s i}\end{array}$ & $\begin{array}{c}\text { Kadar } \\
(\boldsymbol{\mu g} / \mathbf{m l})\end{array}$ & $\begin{array}{c}\text { Rata-rata } \\
(\boldsymbol{\mu g} / \mathbf{m l})\end{array}$ \\
\hline $\mathrm{G}_{1}$ & Kemerahmudaan & 1 & 0,000 & - & - \\
& & 2 & 0,000 & - & \\
\hline $\mathrm{G}_{2}$ & Merah muda & 1 & 0,147 & 0,0024010 & 0,00241365 \\
& & 2 & 0,150 & 0,0024263 & \\
\hline $\mathrm{H}_{1}$ & Bening & 1 & 0,000 & - & - \\
& & 2 & 0,000 & - & - \\
\hline $\mathrm{H}_{2}$ & Bening & 1 & 0,000 & - & - \\
\hline Baku & Merah muda & 1 & 0,000 & - & \\
standar & & 2 & & 0,0052906 & - \\
\hline
\end{tabular}

Keterangan:

$\mathrm{G}_{1}$ : Kue ku dari pasar Tuminting pada penjual $\mathrm{I} ; \mathrm{G}_{2}$ : Kue bolu kukus dari pasar Tuminting pada penjual I; $\mathrm{H}_{1}$ : Kue ku dari pasar Tuminting pada penjual II; $\mathrm{H}_{2}$ : Kue bolu kukus dari pasar Tuminting pada penjual II

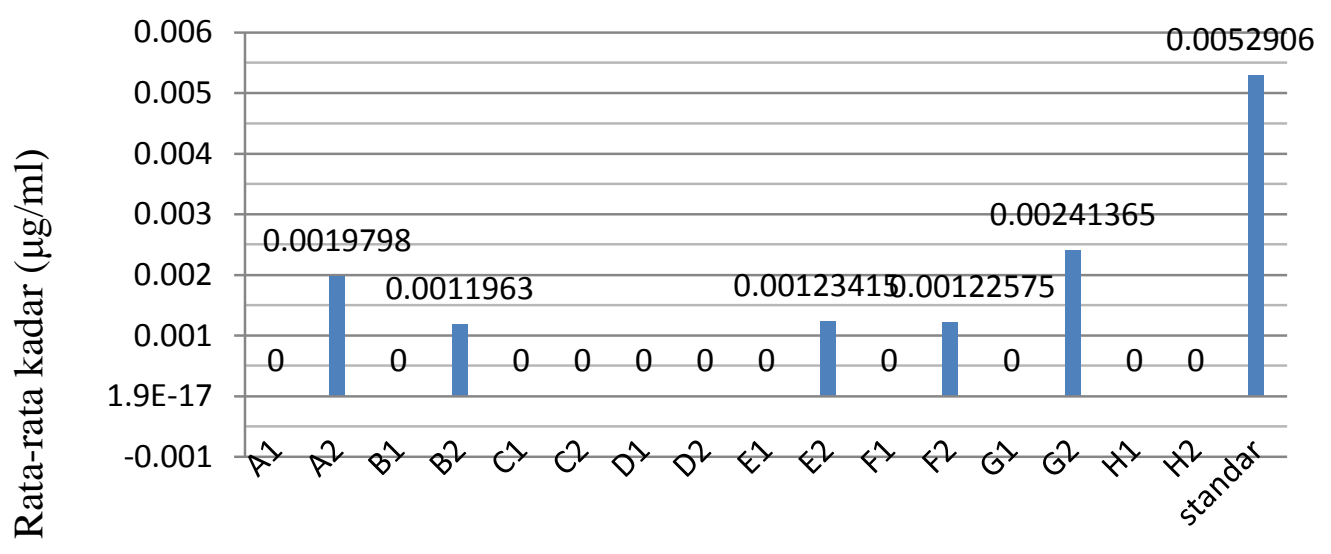

Sampel

Gambar 4. Hasil analisis Rhodamin B pada Jajanan Kue yang Beredar di Kota Manado

Dari keenambelas sampel yang diuji dengan dua kali pengulangan, sebelas sampel $\left(\mathrm{A}_{1}, \mathrm{~B}_{1}, \mathrm{C}_{1}, \mathrm{C}_{2}, \mathrm{D}_{1}, \mathrm{D}_{2}, \mathrm{E}_{1}, \mathrm{~F}_{1}, \mathrm{G}_{1}, \mathrm{H}_{1}\right.$, dan $\left.\mathrm{H}_{2}\right)$ tidak menunjukkan adanya Rhodamin $\mathrm{B}$. Hal ini ditandai dengan larutan uji hasil ekstraksi dari sampel berwarna bening. Lima sampel lainnya $\left(A_{2}, B_{2}, E_{2}, F_{2}\right.$, dan $\left.G_{2}\right)$ menunjukkan adanya Rhodamin $\mathrm{B}$ yang ditandai dengan larutan uji hasil ekstraksi dari sampel berwarna merah muda (Tabel 1-4).

Sampel $A_{2}$ dan $B_{2}$ adalah sampel kue bolu kukus yang diambil dari penjual I dan II di pasar Karombasan. Sampel $E_{2}$ dan $F_{2}$ adalah sampel kue bolu kukus yang diambil dari penjual I dan II di pasar Bersehati, sedangkan sampel $\mathrm{G}_{2}$ adalah sampel kue bolu kukus yang diambil dari penjual I di pasar Tuminting.

Dengan demikian, hasil identifikasi menunjukkan bahwa hanya sampel kue bolu kukus yang diambil di pasar Karombasan, pasar Bersehati dan pasar Tuminting yang positif menggunakan Rhodamin B. Sedangkan untuk sampel kue ku tidak menunjukkan adanya Rhodamin B. Untuk sampel kue yang diambil di pasar Bahu semuanya negatif/tidak menunjukkan adanya Rhodamin B, baik kue ku dan kue bolu kukus. 
Dari penelitian ini menunjukkan bahwa nilai rata-rata kadar Rhodamin B untuk sampel kue bolu kukus yang diambil dari pasar Karombasan pada penjual I yaitu $0,0019798 \mu \mathrm{g} / \mathrm{ml}$ (Tabel 1), pada penjual II yaitu $0,0011963 \mu \mathrm{g} / \mathrm{ml}$, dari pasar Bersehati pada penjual I yaitu $0,00123415 \mu \mathrm{g} / \mathrm{ml}$, pada penjual II yaitu $0,00122575 \mu \mathrm{g} / \mathrm{ml}$ (Tabel 3) dan dari pasar Tuminting pada penjual I yaitu $0,002413650 \mu \mathrm{g} / \mathrm{ml}$ (Tabel 4). Dari hasil ini dapat diketahui ternyata kue bolu kukus dari pasar Tuminting yang memiliki kadar Rhodamin B lebih tinggi dibandingkan dengan kue bolu kukus dari pasar Karombasan dan pasar Bersehati.

Tujuan penambahan Rhodamin B pada jajanan kue adalah untuk menambah kualitas dari kue tersebut dimana warnanya menjadi merah muda terang mencolok sehingga konsumen menjadi tertarik untuk membeli kue tersebut. Selain itu banyak penjual jajanan yang masih menggunakan Rhodamin B karena harganya relatif murah dan mudah didapat.

Zat warna Rhodamin B adalah jenis pewarna sintetik yang dilarang penggunaannya pada makanan sesuai dengan Peraturan Menteri Kesehatan RI No. 239/MenKes/Per/V/1985 tentang zat warna tertentu yang dinyatakan sebagai bahan berbahaya. Rhodamin B adalah pewarna yang biasanya digunakan untuk tekstil dan kertas sehingga sangat berbahaya apabila dikonsumsi.

Penggunaan Rhodamin B pada makanan dalam waktu yang lama (kronis) akan dapat mengakibatkan gangguan fungsi hati maupun kanker. Namun demikian, bila terpapar Rhodamin B dalam jumlah besar maka dalam waktu singkat akan terjadi gejala akut keracunan Rhodamin B. Bila Rhodamin B tersebut masuk melalui makanan maka akan mengakibatkan iritasi pada saluran pencernaan dan mengakibatkan gejala keracunan dengan air kencing yang berwarna merah atau merah muda. Dengan menghirup Rhodamin B dapat pula mengakibatkan gangguan kesehatan, yakni terjadinya iritasi pada saluran pernapasan. Demikian pula apabila zat kimia ini mengenai kulit, maka kulit pun akan mengalami iritasi. Mata yang terkena Rhodamin B juga akan mengalami iritasi yang ditandai dengan mata kemerahan dan timbunan cairan atau udem pada mata (Yuliarti, 2007).
Berbagai penelitian dan uji telah membuktikan bahwa dari penggunaan zat pewarna ini pada makanan dapat menyebabkan kerusakan pada organ hati. Pada uji terhadap mencit, diperoleh hasil yaitu terjadi perubahan sel hati dari normal menjadi nekrosis dan jaringan disekitarnya mengalami disintegrasi atau disorganisasi. Kerusakan pada jaringan hati ditandai dengan terjadinya piknotik dan hiperkromatik dari nukleus, degenerasi lemak dan sitolisis dari sitoplasma, batas antar sel tidak jelas, susunan sel tidak teratur dan sinusoid tidak utuh. Semakin tinggi dosis yang diberikan, maka semakin berat sekali tingkat kerusakan jaringan hati mencit (Anonima, 2006).

Pewarna secara umum mengandung residu logam berat karena pada proses pembuatan zat warna sintetis biasanya melalui perlakuan pemberian asam sulfat atau asam nitrat yang seringkali terkontaminasi oleh arsen atau logam berat lain yang bersifat racun. Di Indonesia, peraturan mengenai penggunaan zat pewarna yang diizinkan dan dilarang untuk pangan diatur melalui SK Menteri Kesehatan RI No. 722/MenKes/Per/IX/88 mengenai bahan tambahan pangan. Akan tetapi, seringkali terjadi penyalahgunaan pemakaian zat pewarna untuk sembarang bahan pangan, misalnya zat pewarna untuk tekstil dan kertas dipakai untuk mewarnai bahan pangan. Hal ini jelas sangat berbahaya bagi kesehatan karena adanya residu logam berat pada zat pewarna tersebut.

Timbulnya penyalahgunaan tersebut antara lain disebabkan oleh ketidaktahuan masyarakat mengenai zat pewarna untuk pangan, dan di samping itu, harga zat pewarna untuk industri jauh lebih murah dibandingkan dengan harga zat pewarna untuk pangan. Lagipula warna dari zat pewarna tekstil atau kertas biasanya lebih menarik (Yuliarti, 2007).

\section{KESIMPULAN}

Dari hasil penelitian yang telah dilakukan dapat disimpulkan bahwa jajanan kue khususnya kue bolu kukus yang beredar di kota Manado masih ada yang enggunakan Rhodamin B sebagai pewarna, sedangkan untuk kue ku tidak menggunakan Rhodamin B sebagai pewarna. Nilai rata-rata kadar 
Rhodamin B yang terdeteksi pada sampelsampel kue bolu kukus yaitu: dari pasar Karombasan pada penjual I $(0,0019798$ $\mu \mathrm{g} / \mathrm{ml})$, penjual II $(0,0011963 \mu \mathrm{g} / \mathrm{ml})$, dari pasar Bersehati pada penjual I $(0,00123415$ $\mu \mathrm{g} / \mathrm{ml})$, penjual II $(0,00122575 \mu \mathrm{g} / \mathrm{ml})$ dan dari pasar Tuminting pada penjual I $(0,00241365 \mu \mathrm{g} / \mathrm{ml})$.

\section{DAFTAR PUSTAKA}

Anonim. 1985. Peraturan Menteri Kesehatan RI No. 239/ MenKes/ Per/ V/ 1985 tentang zat warna tertentu yang dinyatakan sebagai bahan berbahaya. Departemen Kesehatan RI. Jakarta.

Anonim. 1988. Peraturan Menteri Kesehatan RI No. 722/ MenKes/ Per/ IX/ 1988 tentang Bahan Tambahan Pangan. Departemen Kesehatan RI. Jakarta.

Anonim. 1995. Departemen Kesehatan RI. Farmakope Indonesia Edisi IV. Jakarta.

Anonim. 1996. Undang-undang Republik Indonesia No. 7 Tahun 1996 tentang Pangan.

Anonim. 1998. Cara Produksi Makanan yang Baik. Panduan Industri Rumah Tangga. Departemen Kesehatan RI. Jakarta.

Anonim. 2002. BTM: Fungsi dan penggunaannya dalam Makanan diakses tanggal 20 Agustus 2008.

Anonim, 2005. Hindari Makanan Berwarna Sintetis. www. Yahoo. Com diakses tanggal 23 Agustus 2008.

Anonima. 2006. BPOM Temukan Makanan Dicampuri Rhodamin B. http://www.riau.go.id_diakses tanggal 8 September 2008.

Anonimb. 2006. Lebih Akrab Dengan Kue Basah (Ir. Sutrisno Koswara). http://www.ebookpangan.com 2006 diakses tanggal 27 November 2008.

Anonimc. 2006. Metode Analisis PPOMN. Pusat Pengujian Obat dan Makanan. Badan POM RI. Jakarta.
Anonim. 2008. Bahan Tambahan Terlarang dan Berbahaya. http://dinkes.denpasar kota.go.id diakses tanggal 8 September 2008.

Cahyadi, A. 2008. Analisis dan Aspek Kesehatan Bahan Tambahan Makanan. PT. Bumi Aksara. Jakarta.

Desroiser. 1988. Teknologi Pengawetan Makanan. UI-Press. Jakarta.

Khopkar, M. S. 2002. Konsep Dasar Kimia Analitik. Jakarta : Universitas Indonesia.

Sudarmaji. S, Haryono. B, dan Suhardi. 1989. Analisa Bahan Makanan dan Pertanian. Liberty. Yogyakarta.

Winarno, F.G. dan S.F. Rahayu. 1994. Bahan Tambahan untuk Makanan dan Kontaminan. Pustaka Sinar Harapan. Jakarta.

Yuliarti, N. 2007. Awas Bahaya di Balik Lezatnya Makanan. Andi Offset. Yogyakarta. 